\title{
CÓDIGOS SONOROS EN EL RITUAL DE FECUNDIDAD DE LA ALLPA MAMA EN EL INTY RAYMI CAÑARI EN ECUADOR
}

\author{
SOUND CODES IN THE FERTILITY RITUAL OF THE ALLPA MAMA IN THE \\ INTY RAYMI CAÑARI, ECUADOR
}

\author{
Patricia Pauta-Ortiz', Alexander Mansutti-Rodríguez y Diego Apolo ${ }^{1}$
}

\begin{abstract}
En el Ecuador andino se celebra cada solsticio de junio la Fiesta del Inty Raymi (Fiesta del Sol), que se continúa realizando en pueblos de las serranías del antiguo Tawantinsuyo (Guamán-Poma de Ayala 1980 [1613]). En la región cañari del Ecuador se trata de un ritual que abarca varios rituales, entre ellos el de la Allpa Mama (Madre Tierra). En este marco los códigos sonoros, entendidos como aquellos que dan significado a los sonidos que acompañan el ritual, son emitidos por instrumentos musicales como la kipa, el pinkullu, la maraca o la chac cha y el tambor. Este estudio de carácter cualitativo se nutre de la observación participante durante la celebración, entrevistas con informantes de la zona y el registro de imágenes y sonidos. A partir de ello se identificaron los distintos roles de los actores del ritual y la función que cumplen las sonoridades musicales. Como conclusión se resalta la manera en que el quehacer musical de este ritual cañari lleva consigo interacciones entre lo humano y lo no humano, mismas que se entremezclan y son trasmitidas de generación en generación.
\end{abstract}

Palabras claves: códigos musicales, Cañari, Inty Raymi, Allpa Mama, etnomusicología.

Inty Raymi (Fiesta del Sol) is a festival held every June solstice in the Andean Ecuador, specifically in the villages of the mountainous areas of the ancient Tawantinsuyo (Guamán-Poma de Ayala 1980 [1613]). In the Cañari region of Ecuador, Inty Raimi consists of several rituals, one of them being the Allpa Mama (Mother Earth). The sound codes in the festival, i.e., the codes that give a sense to the sounds accompanying the ceremony, are made by musical instruments like the kipa, the pinkullu, the maraca or chac cha, and the drum. This qualitative study draws on participant observation during the event, interviews with community informants, and image and sound recordings. Based on that, the different roles of the participants of the ritual and the function of the musical sonorities were identified. The last segment of this article highlights the way in which the musical activities of this Cañari ritual involve interactions between the human and the non-human, interactions that are passed down from generation to generation.

Key words: Music codes, Cañari, Inty Raymi, Allpa Mama, ethnomusicology.

En este artículo se analizan los códigos sonoros que los instrumentos musicales producen en el ritual de la Allpa Mama (Madre Tierra) como parte del Inty Raymi (Fiesta del Sol). En tal sentido, se entenderá por código sonoro al conjunto de significaciones diferenciadas que los sonidos musicales transmiten al momento de ser ejecutados y que permiten intercambiar información compartida por los participantes. Además, se identifican los personajes musicales que en ella participan y el rol que cumplen.

Las comunidades cañaris habitaron desde tempranas épocas en la región sur del Ecuador, en las actuales provincias de Azuay, Cañar, Loja Norte y Chimborazo Sur. Ancestros de los Cañaris fueron consolidando su presencia en esta zona hasta dar paso a la sociedad sur-andina agro-alfarera conocida como

\footnotetext{
${ }^{1}$ Universidad Nacional de Educación, Azogues, Ecuador. diana.pauta@unae.edu.ec; alexander.mansutti@unae.edu.ec; diego.apolo@unae.edu.ec
} 
Cultura Narrio Temprano hace aproximadamente 2000 años AC. Siendo ya Cañaris fueron sometidos por los Incas 50 años antes de la llegada de los españoles. Se trata por tanto de una sociedad con raíces preincaicas, cuya profundidad temporal está por determinarse. Collier y Murra (2007) mencionan que su lengua originaria había desaparecido. Estos mismos autores asumen que únicamente los horizontes arqueológicos más tardíos y que muestran influencia incaica son representativos de los Cañaris. En la actualidad esta población habla el castellano y una modalidad de la lengua kichwa. Además, mantienen tradiciones sincréticas que combinan elementos culturales propios, incas y europeos (Garzón 2012). Los Cañaris son, en términos de Descola (2012), una cultura animista por cuanto en el animismo la naturaleza está englobada en la cultura. Su vestimenta es un marcador cultural que permite distinguirlos del resto de los pueblos kichwa hablantes de la sierra ecuatoriana (Figura 1). Hoy, los Cañari en el Ecuador habitan principalmente en zonas urbanas y rurales de las provincias del Azuay y del Cañar.

En el mundo kichwa se conocen como taitas a los indígenas varones, ancianos de la comunidad que portan los conocimientos y saberes propios de su cultura y que por ello han ganado respeto. Mientras que los yachak además de tener estas facultades, están autorizados para realizar rituales, invocaciones, sanaciones y actos sagrados. Es así como estos taitas comuneros ratifican que la lengua cañari desaparece por la imposición de la lengua kichwa y posteriormente del castellano. Afirman también que la tradición oral se construye desde el cotidiano a partir de palabras, nombres y frases cañaris mezcladas con el kichwa (Figura 2).
Como el resto de pueblos andinos, los Cañari conformaron una sociedad basada en las actividades agrícolas. Ello conllevó al interés y conocimiento de la astronomía, lo que a su vez permitió el control de las actividades sociales relacionadas con las estaciones y los ciclos naturales. Como consecuencia de la observación y valoración del movimiento de cuerpos celestes, se pudieron periodizar los ciclos climáticos y se establecieron leyes de armonía e interrelación con el cosmos que trascendieron en sus formas de vida vinculadas a las expresiones artísticas (Enríquez 2005). Estas leyes se manifiestan en las festividades de la nacionalidad cañari asociadas a las grandes celebraciones agrícolas de siembra y de cosecha.

El ciclo agrícola cañari se caracteriza por la presencia de ceremonias complejas en las que se integran varios rituales. En ellos la música cumple un rol protagónico. De todas las celebraciones adscritas al calendario agrícola, el Inty Raymi (Fiesta del Sol) es la de mayor solemnidad. En ella se registran tres rituales: el ritual de la Intywatana (amarre al Sol) el ritual del Haway (canto agrícola) que acompaña en los campos la cosecha del maíz y el trigo; y el ritual de la Allpa Mama (Madre Tierra) donde especialistas rituales y seres extraordinarios promueven junto a los comuneros la fertilidad. Este ritual es el objeto del análisis propuesto.

Las manifestaciones que se observan en esta celebración en el marco del Inty Raymi cañari son clara evidencia de la coherencia de su concepción cosmogónica, llena de simbolismo mágico-religioso (Milla 2008), donde la fertilidad de la Allpa Mama está asociada al benefactor Sol como ente dador de vida, con sus disposiciones éticas, estéticas y las prácticas sociales asociadas. La base ideológica cañari es la concepción

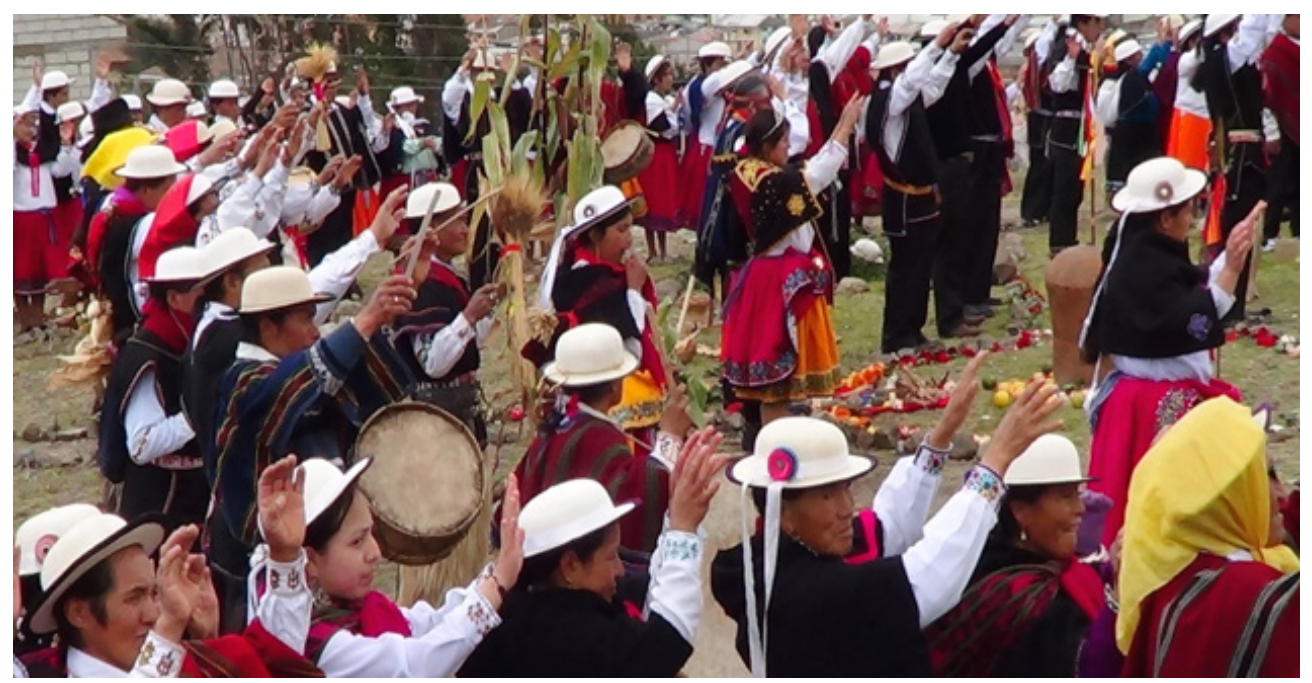

Figura 1. Comunidad cañari en el ritual del Inty Raymi.

Cañari community at the Inty Raymi ritual. 


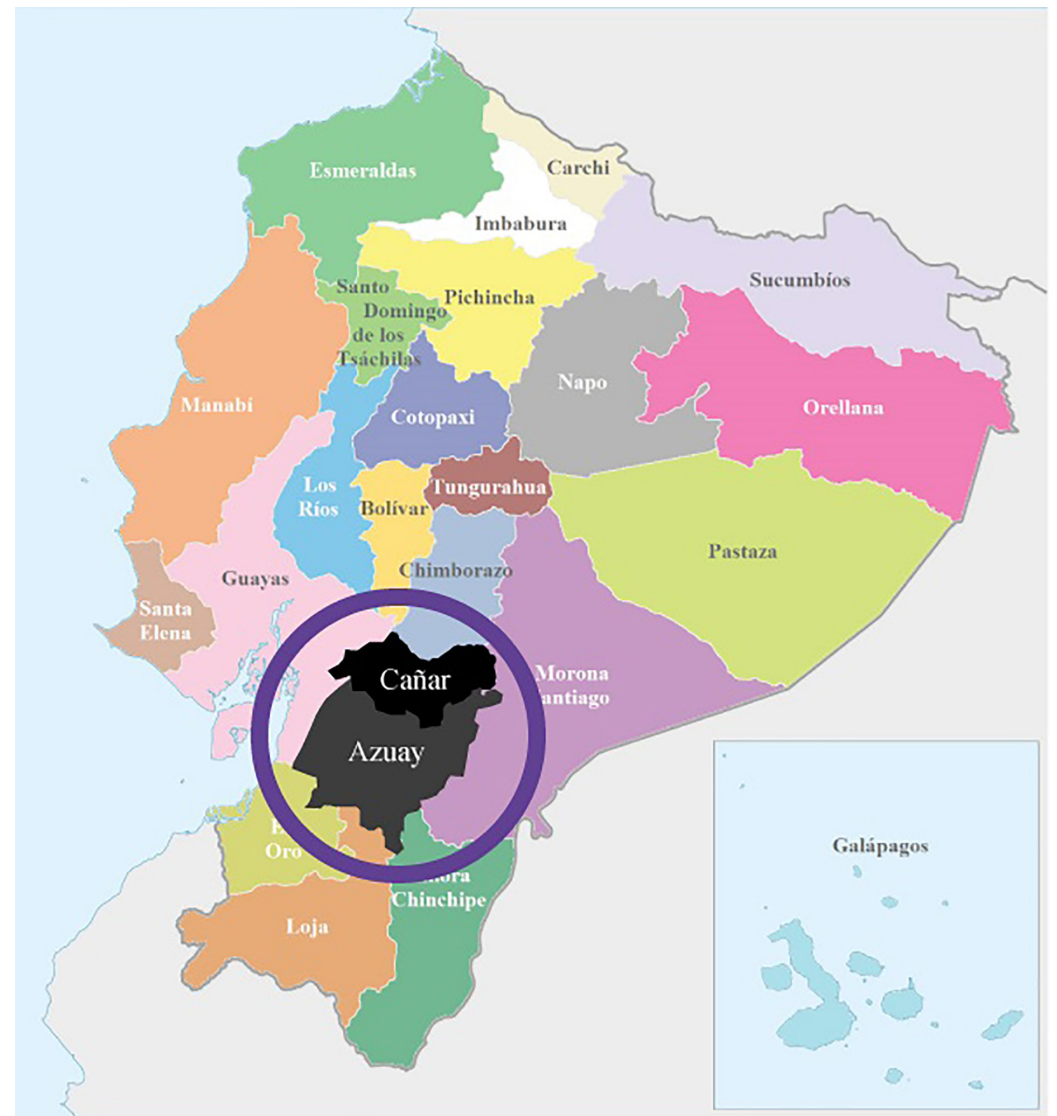

Figura 2. Mapa de Ecuador.

Map of Ecuador.

cosmogónica andina que resulta de la síntesis del aporte cultural Inca con las particularidades que lograron sobrevivir de su propia cosmovisión (Cordero 2007).

Los Cañari dedican su cotidiano a actividades agrícolas como el cultivo de tubérculos, así como también del maízy el trigo. Sin embargo, en su sociedad se han establecido otras tramas desde sus relaciones sociales y ahora desarrollan también otras actividades como las de empresarios agrícolas, comerciantes y prestadores de servicios. A pesar de la complejidad social adquirida, los Cañaris mantienen tradiciones, mitologías, rituales, prácticas curativas y gastronómicas propias, todas dependientes de sus formas de interpretar el mundo y las relaciones con su entorno, que dan gran importancia a las montañas, las cascadas, las lagunas y a los espíritus Apus que habitan en ellos, a quienes reconocen competencias culturales que son universales a los seres humanos: el habla, el trabajo, las relaciones humanas, los sistemas de parentesco y matrimonio, la organización política, prácticas espirituales y sanitarias, relaciones de reciprocidad e intercambio, el pensamiento, entre otros, de manera general y shamánicas en particular.
Estas competencias compartidas entre sus miembros son marcos de referencia que guían sus relaciones, regulan la convivencia y dan significación a cada contexto. A partir de ellas, se practican ritualidades con sentido que facilitan las relaciones entre todos los seres culturales animados que allí conviven (Ruiz-Olabuenaga e Ispizua 1989).

Dentro del ritual de la Allpa Mama cañari, la música se convierte en portadora de mensajes sonoros que permiten entender y analizar las relaciones que se desarrollan entre los actores del rito, unos humanos y otros no humanos, pero todos compartiendo una misma cultura. Aquí se aplica el principio de complementariedad, característico de la filosofía andina (Esterman 2006). La música en el rito cañari debe ser entendida como un hecho social total (Mauss 1991); es decir, como un hecho en el que se concentran factores ideológicos, simbólicos, sociales, políticos y económicos, sin los cuales sería imposible entender su lugar en la sociedad. En este caso, la comprensión de los códigos sonoros compartidos obliga a incorporar en su análisis conceptos desde la cosmovisión andina (Esterman 2006). 


\section{La Música desde la Cosmovisión Andina}

Durante el esplendor del Imperio del Tawantinsuyo en el que coexistieron y se integraron diferentes culturas sometidas al dominio de los Incas, alcanzaron su auge la cosmovisión andina de sello incaico y sus festejos asociados. Siendo pueblos agricultores que controlaban diversos pisos ecológicos en el marco de una estacionalidad climática, desarrollaron un calendario de fiestas ancestrales que tenían como eje a los solsticios y equinoccios (Enríquez 2005). Se trata de fiestas que acompañan los ciclos agrícolas en el marco de su visión animista.

En este devenir cosmogónico se hacen efectivas las relaciones simbólicas de los seres humanos y los seres extraordinarios -el sol, la luna, la tierra, las lluviascomo promotores de la fecundidad. Estos vínculos se desarrollan a partir de los roles y funciones de la semiótica de los timbres musicales enraizados en el pensamiento colectivo cañari. En el ritual, tienen presencia protagónica los campos de comunicación entre actores provenientes de las diferentes dimensiones de la cuatripartición cañari. Así, por ejemplo, la relación entre el sol, la luna, las deidades y los espíritus de los ancestros difuntos que conviven en el Hana pacha (el mundo de arriba, lo alto) con los seres humanos, animales y plantas que ocupan el Kay pacha (el mundo de aquî), se efectúa con el sonido de la kipa. Las relaciones de los comuneros cañaris con los seres míticos de las montañas, con el espíritu del Allpa Mama, quienes coexisten con el de los ríos subterráneos y el de las semillas que habitan el Uku pacha (el mundo de adentro) se efectúa con las sonoridades del pinkullu, dimensión en la que también se encuentra el corazón de la Madre Tierra al que se conectan con el ritmo del tambor. Con las sonoridades de la maraca realizan la purificación de la tierra, el agua, el fuego y el aire que habitan en los pacha, e invocan la sabiduría que se encuentra en el Hawa pacha (dimensión difusa), que desarrolla relaciones entre los seres promotores de la fecundidad en beneficio de todos quienes habitan el Kay pacha.

En el mundo Inca, el orden está constituido por la tripartición que reconoce tres dimensiones: el mundo de los cielos, el mundo terrenal y el inframundo (Enríquez, 2005). La peculiaridad en la cosmovisión cañari es que a esta tripartición se le añade una cuarta, el Hawa pacha, que, a diferencia de las tres primeras, no tiene referentes de orden espacial, es ubicua, está en todas partes. Se trata de una dimensión omnipresente en el tiempo y en el espacio, que se caracteriza por concentrar la sabiduría y los que habitan en los distintos mundos. Este accionar, que echa raíces en las prácticas ancestrales, se efectúa con instrumentos musicales como, la kipa (Martínez 1986), que data su presencia desde el periodo precerámico (Idrovo 1987). Es así como, las sonoridades y coloraciones responden a cada práctica agraria específica, como en el caso de las afinaciones agudas del pinkullu pentafónico que se emplean para fecundar a la Allpa Mama, nombre con el que los comuneros cañaris designan a la Madre Tierra, a la que consideran un ser vivo y sagrado.

Es así como en estos rituales ancestrales la música se convierte en mensajes dirigidos al entorno, cuyo fin es fortalecer las relaciones culturales de los humanos en su conjunto y de los humanos con los entes extraordinarios que dan continuidad a la vida.

En el ritual de la Allpa Mama se convocan con las sonoridades de la kipa a los seres y deidades que son propiciadores de vida y se encuentran representados como pares complementarios de una unidad, así el Sol-deidad masculina y su complemento la Luna como deidad femenina. Lo mismo en el caso de la Allpa Mama deidad femenina con la de Pachakamak como deidad masculina, quien organiza el mundo. Estos opuestos complementarios representan la dualidad, que es parte del principio conceptual del pensamiento andino (Lajo 2002). Estos rituales propician una relación de respeto y convivencia entre el mundo visible y el mundo invisible, de acuerdo con los aportes de Estermann (2006).

Lo habitual es que el runa -ser humano- se mantenga en comunicación con sus pares humanos y las entidades mediante distintos lenguajes, entre ellos el sonoro musical, para establecer la comunicación necesaria que permita mantener relaciones de reciprocidad con esas fuerzas no humanas pero también culturales del mundo. El aliento, acto al que el pueblo de los cañari nombra como samay, convertido en sonoridad musical en el canto o en la ejecución de aerófonos, es considerado como energía transformada en fuerza generadora de vida, poderosa e imprescindible para la existencia (Hill y Chaumeil 2011). En las ceremonias, la música hecha instrumentación, canto o silbido, es un mecanismo, entre otros, que ayuda a hacer efectiva la relacionalidad entre los seres que habitan las dimensiones que corresponden a los diferentes niveles de la cuatripartición cósmica que caracteriza al mundo (Figura 3).

Los símbolos y códigos musicales son, para los comuneros cañaris, una modalidad ancestral de comunicación, contacto y vivencia con lo sagrado. Ello es lo que se comprende como función sonora. La música deviene un canal mediático que se da entre los seres humanos, y entre estos y los no humanos, entre el mundo tangible e intangible, y que ocurre a través de sonidos que son emitidos por instrumentos musicales con timbres de personalidad propia, que suenan asociados según tiempos intencionados para otorgar una densidad sonora en la que ocurren polílogos entre todos los actores culturales presentes.

La complejidad de este polílogo sonoro adquiere mayor densidad cuando se armonizan las voces de los instrumentos musicales citados con otras fuentes 


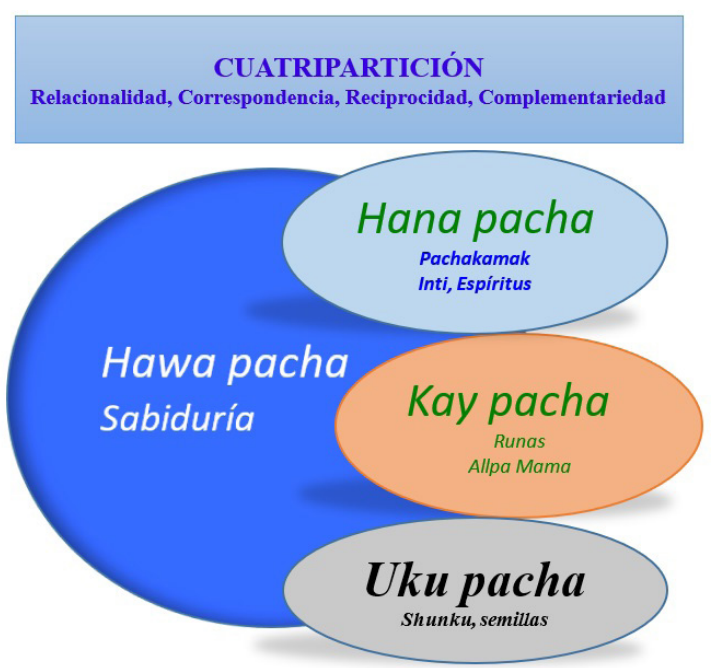

Figura 3. Niveles de la cuatripartición cósmica.

Levels of the cosmic quadripartition.

sonoras como las del ritmo del corazón de la Madre Tierra. Esta acción sonora explica la preferencia de los músicos cañaris por alcanzar una calidad tonal 'densa' (Stobart 2010) con los respectivos armónicos que logran articular en la interpretación durante el ritual.

En el ritual de la Allpa Mama, la música es el hilo conductor. Su función principal es lograr, a través de los sonidos y melodías, que se establezcan relaciones recíprocas para hacer producir la tierra, alineándola a los poderes significativos del cosmos. Ello se logra poniendo en práctica un sistema de interacción -dádiva y ofrenda-, como se puede observar más adelante.

La realización de los ritos que forman parte de esta celebración cumple además las funciones de actualizar las normas y patrones de conducta, de restablecer los códigos morales, la escala de valores y el contenido simbólico que condensa esta cosmovisión.

Tanto los músicos como los oyentes se encuentran vinculados a través de sus rasgos identitarios de manera que la valoración que unos y otros hacen del hecho musical involucre sus concepciones compartidas del mundo, sus valores y prácticas sociales. Si el músico y el escucha se forman en el mismo marco cultural, ambos compartirán códigos musicales similares (Pauta 2017a). Así ocurre porque la música es el resultado de las necesidades, habilidades y destrezas que músicos y escuchas adquieren en el seno de los colectivos en los cuales se desarrollan. Por ello es por lo que la perspectiva culturalista exige que se registre la asociación de las sonoridades y melodía con sus significaciones extra musicales, y las normas que las rigen. Dentro de este contexto ritual, la música actúa como un elemento catalizador dentro de las redes vinculares humanas. Las sonoridades se constituyen en un poder de comunicación con capacidad para influir a nivel físico, psicológico y espiritual del individuo y la comunidad (Benenzon 2008).

En las localidades indígenas, la realización de los ritos cumple clara y reiteradamente las funciones de mecanismos de resistencia y creatividad cultural frente a los intentos de imposición de las maneras dominantes de pensar (De la Peña 1998). Si no hubiera sido así, los ritos ancestrales no se hubieran transformado para sobrevivir a las arbitrariedades de las políticas de 'extirpación de idolatrías' (Acosta 1987) o frente a políticas como el blanqueamiento y la vergüenza étnica (Mansutti-Rodríguez 2006). La resistencia de los pueblos originarios, a veces silenciosa y clandestina, ha desarrollado mecanismos frente a las instituciones que buscan subordinarlos desde los discursos del poder, usando la descalificación de las artes propias frente a la hegemonía de un supuesto arte universal. Mientras se imponía en las iglesias la ejecución de los cordófonos y aerófonos (Pauta 2013), en las comunidades estos instrumentos eran reinterpretados para articularse a los ritmos y cadencias no europeos de la música ancestral. La resistencia era complementada con la creatividad. No se pueden interpretar los cambios y las resignificaciones musicales suscitadas en el transitar de los últimos 500 años sin entender la dialéctica de la relación entre colonizadores y colonizados.

\section{Materiales y Métodos}

Los modos convencionales de representación gráfica de la música occidental aplicados a la música de transmisión oral cañari reflejan en forma parcial y superficial las prácticas sonoras de este pueblo indígena. Reconocidas estas debilidades, diferentes autores (Fernández-Calvo 2007; Pauta 2017b), han propuesto otros sistemas de notación musical alternativos para estos fines, con la intención de ofrecer modalidades de transcripción más adecuadas a expresiones musicales para las que la descripción por los estándares occidentales no es suficiente. A pesar de sus limitaciones este recurso ayuda a explicar, desde los símbolos formales de la música, los mensajes y saberes ancestrales que el pueblo cañari transmite en el ritual musicalizado de la Allpa Mama.

Para explicar la complejidad de la música como hecho cultural acorde al criterio estético cañari, se efectuaron dos tipos de análisis: musicológico y etnomusicológico. El primero, con enfoque a la obra como objeto sonoro -universalista ${ }^{1}$ - y el segundo con enfoque antropológico musical -humanista ${ }^{2}$ particular-(Grebe 1981). Esta adaptación metodológica heterogénea es una respuesta a las limitaciones de eficacia explicativa y validez hermenéutica que ocurren al momento de analizar la música del ritual de 
la Allpa Mama desde la aproximación convencional, que no fue suficiente para explicar las estéticas propias de los músicos cañaris, ni la función mágico-religiosa que cumplen los códigos sonoros en este ritual.

El primer enfoque fue el universal, con sus técnicas de transcripción y descripción musical. La transcripción que se presenta en este artículo emplea el sistema de notación musical tradicional occidental, recurriendo al uso del pentagrama, las claves, las armaduras de clave, las cifras y barras de compás, notas, figuras y silencios. Sin embargo, esta forma de análisis del diálogo de los taitas, no tendría sentido si no se realiza la descripción escrita que detalla la parafernalia del contexto del ritual cañari. Esto significa que la escritura musical empleada es una aproximación a aspectos formales, puesto que esta música étnica cañari fue creada bajo sus propios parámetros estructurales que le caracterizan; es decir, es incronometrable puesto que este 'diálogo sonoro' no se encuadra a una regularidad de tiempo y compás, y es asimétrico. Estas características son propias de su esencia.

Esta música fue creada para ser escuchada -no escrita-, y su función está determinada para generar relaciones entre los humanos con las deidades y con los espíritus. Para ello se necesitan instrumentos cuya intensidad sonora viaje las distancias correspondientes para que sus mensajes sean escuchados y comprendidos por los humanos y por las entidades de los distintos mundos. Así lo reflejan en este ritual los timbres graves y continuos del sonido imponente de la kipa, los timbres agudos que emite el pinkullu en su línea melódica y las polirritmias generadas por los instrumentos de percusión.

Los instrumentos que participan en este ritual de la Allpa Mama son elaborados por los propios ejecutantes indígenas y sus afinaciones no se ajustan a la escala cromática occidental. En el caso de la línea melódica del pinkullu, algunos de sus intervalos son inferiores a semitono; por tal motivo su transcripción es compleja debido a que es impautable, como lo menciona De Carvalho (1964). El aprendizaje musical se produce en forma oral y la ejecución instrumental puede variar de acuerdo con circunstancias como la posición corporal del instrumentista, su estado de ánimo o el efecto que le produce la ingesta de bebidas propias del ritual como la chicha de maíz.

En la etnomusicología, al margen de la escucha y la aproximación gráfica del sonido que resulta de la observación directa, fueron necesarias las fuentes primarias de información para asociar y comprender los valores y estéticas que dan origen y significado al quehacer musical cañari. Ello explica que, para entender la música en estos rituales, llevemos 20 años recopilando y analizando las manifestaciones musicales de las comunidades cañaris ecuatorianas que dan sentido a tres años consecutivos de trabajo de campo en la celebración del Inty Raymi.

Nuestro segundo enfoque fue el etnomusicológico. Desde este abordaje interactúan conceptos de la Musicología y de la Antropología, especialmente con la Etnología, entendida como la disciplina que analiza la cultura de cada pueblo. Solo con el empleo de instrumentos descriptivos y analíticos de la Antropología Simbólica y de la Antropología Sociocultural podemos comprender la función de la música en el contexto sociocultural de esta fiesta.

Desde la Antropología Simbólica se toman en consideración los significados de los símbolos tanto musicales como extra-musicales y como se asocian para dar sentido a estas formas de interacción. Y desde la Antropología Sociocultural se hace referencia a la organización social que regula las relaciones entre los seres humanos y otros entes culturales. Desde estas perspectivas se puede entender como se ordenan las lógicas de la creación, adaptación y reexposición de las prácticas musicales en el contexto ritual (López 1995).

Esta interacción intradisciplinar permite tener una visión holística de la relación entre lo extra-musical y el quehacer musical. La visión musicológica que se adopta en este estudio toma en cuenta el análisis musical y la organología, para cobrar sentido en el contexto ritual (Nettl 1964).

Se parte desde un enfoque cualitativo y de alcance descriptivo-exploratorio. Las técnicas utilizadas fueron la observación participante, el registro de hechos en diarios de campo, fichas de observación y entrevistas a profundidad a cantantes y ejecutantes de los instrumentos del ritual, como Taita Yacu y Taita Amaru, ambos yachak ${ }^{3}$ cañaris que presidieron las ceremonias. Las ceremonias y prácticas musicales fueron recopiladas en formato audiovisual, material que favoreció la decodificación de las estructuras musicales, las prácticas sociales, sus contenidos y significados. Ello también permitió analizar desde los enfoques universal y humanístico particular, [...] el uso de la música como símbolo y emblema de identidad [...] Cañari (Cámara de Landa 2003, 2010:80).

\section{Resultados}

En el ritual de la Allpa Mama se involucran los elementos constitutivos de la vida como el agua, el aire, la tierra y el fuego; deidades como el Sol o Inty, la Allpa Mama y Pachakamak y los espíritus de los ancestros que velan por el bienestar de sus descendientes. Todas estas entidades son musicalmente invocadas y convocadas por el especialista ritual conocido como yachak para participar en esta ceremonia, para ello, en la convocatoria la música es un instrumento de comunicación privilegiado. 
Son los músicos los que les otorgan características acústicas a los instrumentos musicales para obtener resultados sonoros preestablecidos para el ritual. A su vez, estos les dan los atributos físicos y sonoros para ser aceptados culturalmente.

Para los comuneros cañaris, la bondad de su vida, la fertilidad de la tierra y la eficacia en la producción de alimentos son el resultado de la armonía entre la Allpa Mama, el Runa -ser humano-, el cosmos y sus ancestros. Esta relación se explica a través de la analogía makipurarishpa -apoyándonos y retribuyéndonos- que realiza el 'Taita Amaru' -yachak- cuando pide a sus comuneros, vivir en armonía y tratar bien a la Madre Tierra. En posición de rodillas dirige sus oraciones hacia el corazón-shunku- de ella y solicita su bienestar. Seguidamente, con las melodías interpretadas con el pinkullu crean las condiciones para fecundarla. Todo ello es posible porque la episteme animista de la cosmovisión andina cañari lo permite (Figura 4).

El ritual de la Allpa Mama se celebra en un centro ceremonial denominado Icto Cruz. A este lugar van a festejar los comuneros cañaris, sus taitas y yachak en el día del solsticio de verano, el 21 de junio; llevan consigo sus instrumentos musicales, portadores de lenguajes estéticos sonoros, que les permiten articularse bajo un sistema de comunicación sonoro particular.

Los instrumentos que se utilizan son la kipa, el pinkullu, el tambor y la maraca, el sonajero de semillas, cada uno de ellos comunicando mensajes que interrelacionan las entidades de las cuatro dimensiones de la cuatripartición cañari.
A partir de ello los describimos según su orden de entrada en el polílogo sonoro:

\section{Kipa -Caracol marino-}

Los grandes caracoles marinos (Strombus galeatus) (Martínez 1986), son conocidos en el pueblo kichwa cañari como kipa. Ellos son de diferentes tamaños, con forma redonda y estructura en espiral tanto en su exterior como al interior. Abriéndoles un orificio de insuflación en la parte posterior pueden ser usados como trompetas (Coba 1981), lo que le da la categoría de aerófono según las clasificaciones de Hornbostel y Sachs (1961) e Izikowitz (1935) (Figura 5).

Las conchas marinas, conocidas como trompetas, pututo o kipa, por su sonoridad llegaron a constituirse en instrumentos muy valiosos y de gran significado para ser utilizadas en las ceremonias. La potencia de su mecanismo sonoro depende de la intensidad del aire insuflado que efectúa el músico kipero en la embocadura abierta que le realizan a la kipa. El yachak interpreta la kipa generando sonoridades en Mi bemol (Mib), que va dirigiendo paulatina y sucesivamente hacia los cuatro puntos cardinales y en contra del sentido de las agujas del reloj, para solicitar permiso a todos los entes poderosos del cosmos cañari. Así se inicia la celebración, convocando a Taita Inty -Padre Sol-y Pachakamak -organizador del cosmos y la tierra-. La calidad, altura y duración que alcanza el sonido de este instrumento está condicionado por la técnica del soplo, es decir, la intensidad y fuerza de aire que

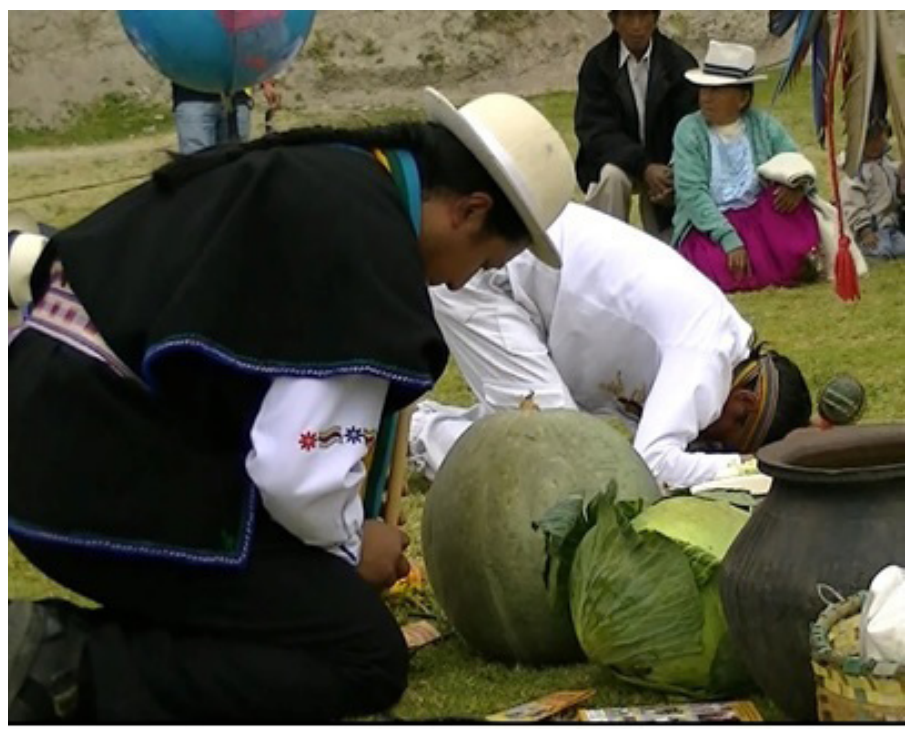

Figura 4. Yachak interpreta el pinkullu en el ritual de fecundidad de la Allpa Mama. Yachak plays the pinkullu during the Fertility ritual of the Allpa Mama. 


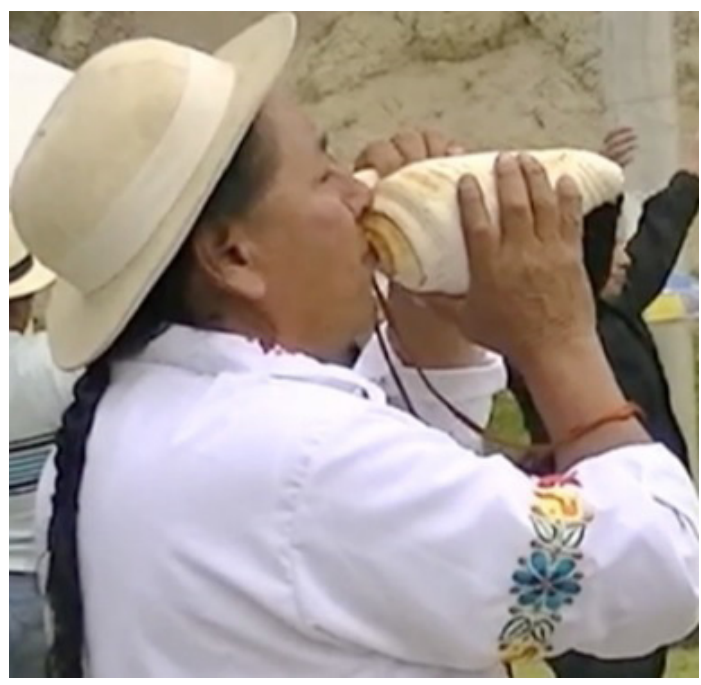

Figura 5. Kipa.

Kipa.

el músico intencionadamente distribuye durante la ejecución, por la posición y vibración de los labios sobre el orificio de la kipa. Emiten diferentes toques -sonidossegún la simbología empleada por los músicos y cada uno de ellos corresponde a un significado y cumple una función conocida por toda la comunidad.

En el inicio del ritual, el yachak mayor, Taita Yacu, interpreta la kipa iniciando un compás antes de que suenen los otros instrumentos musicales que integran este diálogo sonoro. Esto reinvindica que es el sonido de la kipa el que solicita el permiso a las deidades. Luego de ello, ocurre una sucesión de sonidos largos y cortos que convocan la apertura del Uku pacha a fin de que los Apus, espíritus y seres que viven en su interior, puedan asistir al evento. Este curso melódico de la kipa se encausa por el cromatismo Mi y (Mib) en valores largos -representados en la transcripción musical mediante las ligaduras de prolongación- y breves -corcheas y semicorcheas-, con algunas pausas de respiración -silencios de corchea- en el curso de la ejecución.

\section{Pinkullu -Flauta vertical con embocadura-}

El pinkullu, conocido también como flauta vertical de pico, es interpretado por el yachak Amaru en la ceremonia de fecundidad de la Allpa Mama. Se describe como un instrumento aerófono de tubo abierto, de carrizo, que tiene en la parte superior una boquilla con un dispositivo de madera que deja un canalete para la insuflación. En la parte posterior tiene un agujero que junto con los cuatro agujeros de la parte delantera constituyen los mecanismos de obturación para la digitación.
El Taita Amaru interpreta el pinkullu pentafónico en un total de 15 compases. El músico intenta mantener la misma fórmula rítmica durante toda la ejecución. La melodía presenta ligeras variantes como consecuencia de la dificultad que provoca en su respiración la posición corporal de rodillas adoptada, con su dorso doblado y abdomen contraído con dirección a la tierra al momento de interpretar. La alteración sonora que esto produce se vuelve notoria en el séptimo y octavo compás del registro (Figura 6).

La línea del pinkullu no evoluciona de acuerdo con los marcos de la tonalidad. En el primer tramo de la melodía -hasta aproximadamente el compás 9- el Mi natural -apoyado por el Mib- insinúa funcionar como un eje central, desde el cual se producen algunos saltos descendentes de cuarta aumentada -nota de destino: Si bemol-. A partir del compás 10, cuando el Mib comienza a desplazar al Mi natural en calidad de eje central, los saltos se vuelven ascendentes y de cuarta justa -nota de destino: La bemol-. El músico emplea, además, algunas bordaduras diatónicas -compases 4 y 6-, prolongación de algunos sonidos -indicados en la transcripción por medio de las ligaduras de prolongación- y un glissando descendente característico, sobre las notas Si bemol y Mi bemol. Estos efectos sonoros, junto con su posición corporal, acentúan la metáfora de la fecundación de la Allpa Mama. Según el pensamiento de los músicos cañaris, los instrumentos musicales se dividen en machos y hembras (Godoy 2005). En este caso, el pinkullu para los Cañaris es macho. Actúa fundamentalmente sobre el Kay pacha -mundo del aquí- y el Uku pacha -mundo de adentro- ${ }^{4}$ (Figura 7).

Los sonidos agudos de los aerófonos, según la cosmovisión andina, están asociados a la demanda de los bienes necesarios para que la tierra se fecunde, por ejemplo, la lluvia. Estos son códigos sonoros muy bien comprendidos por los músicos y por los comuneros cañaris. En este caso la comunicación es con el Hana pacha -dimensión de las deidades- y el Uku pacha -adentro de la tierra-. Una vez instalado el rol del instrumento y su melodía en el mundo de los valores culturales, los instrumentos serán elaborados e incorporados al acto ritual, le será definida la intención y se realizará su interpretación en el momento adecuado.

\section{Wankar -Tambor - Bombo-}

El bombo interpretado en este ritual es de tamaño mediano, conocido también por los músicos de esta localidad como wankar. Es un idiófono de membrana que consta de una caja de resonancia de madera cuyas bocas están cubiertas por un parche superior hembra -warmi- y otro inferior macho -kari-, sujetos con aros de madera que se encuentran tensados por unas soguillas en 

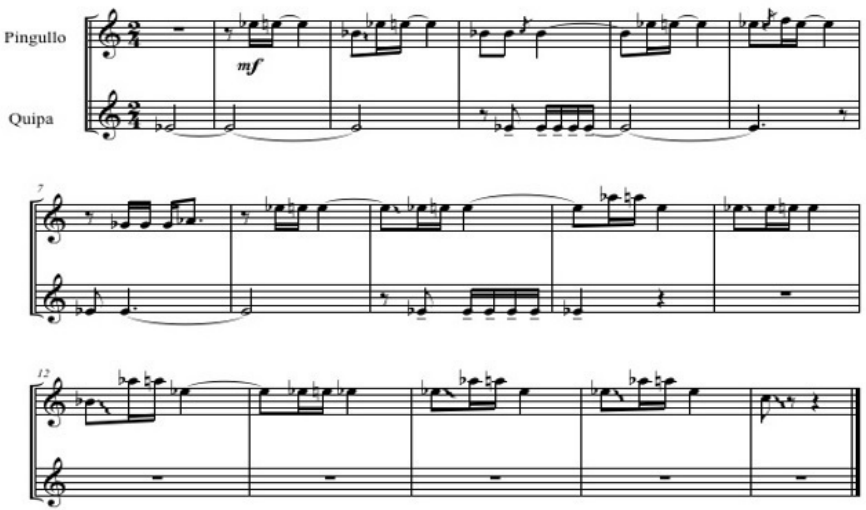

Bombo
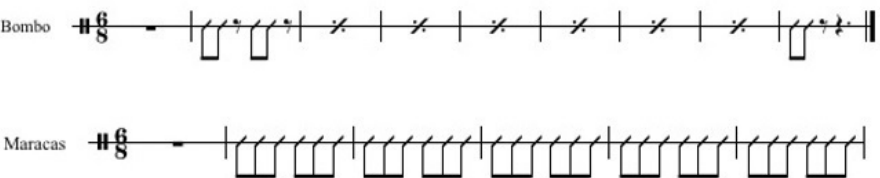

Figura 6. Transcripción musical del diálogo sonoro. De Patricia Pauta Ortiz, registrado en el Inti Raymi del 2013, en Icto Cruz, Azuay, Ecuador.

Musical transcription of the sound dialogue From Patricia Pauta Cruz, registered in the Inti Raymi 2013, in Icto Cruz, Azuay, Ecuador.

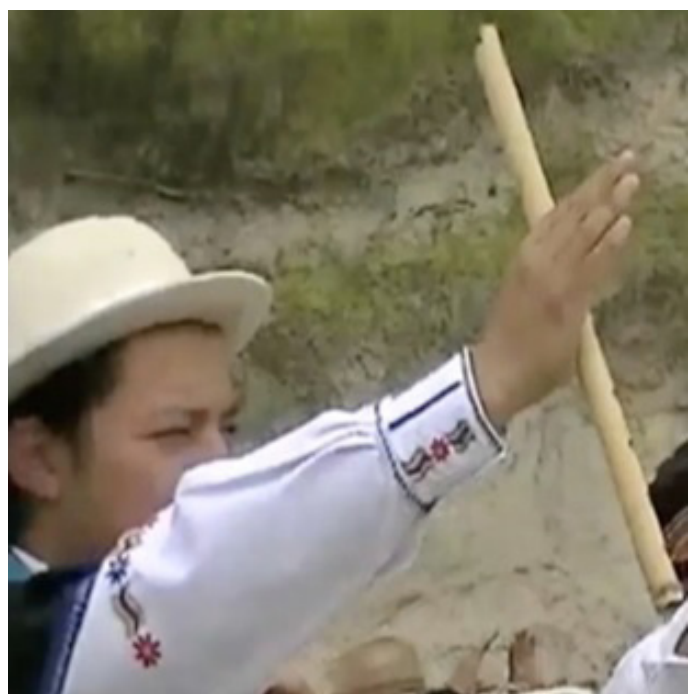

Figura 7. Pinkullu.

Pinkullu.

forma de zig-zag. En medio de la caja de resonancia se encuentra un orificio para que el aire comprimido tenga salida al exterior. Este instrumento es interpretado con un percutor denominado mazo. En este ritual, el sonido del bombo -tuntun, tuntún- desde el Kay pacha se sintoniza con el pulso de la tierra, generado por el corazón -shungu de la Allpa Mama que se encuentra en el Uku pacha. Es un ejercicio de sintonía entre la Madre Tierra y los seres que habitan en ella. Con esta rítmica, el bombo crea la armonía con la melodía del pinkullu, cuya función es garantizar la fecundidad de la Madre Tierra (Figura 8).

El bombo -wankar- es ejecutado a partir del segundo compás de la línea de la kipa, reproduciendo hasta el compás 8 el motivo rítmico de dos corcheas -silencio de corchea- por cada tiempo, en compás de 6/8. Finalmente, en el compás 9 , concluye con dos corcheas sobre el primer tiempo.

\section{Maraca o chac cha -Sonajeros de semillas-}

El cuarto instrumento es un sonajero de semilla que puede tomar la forma de chac cha o de maraca. Cuando es una maraca se elabora con una calabaza redonda, pequeña y seca que es la caja de resonancia en cuyo interior se depositan semillas. La calabaza posee una extensión de madera que permite sujetarla (Rivera 2015) y accionarla con ligeros movimientos para producir las sonoridades. Cuando es una chac cha, se trata de sartales de semillas secas. En ambos casos se trata de sonidos que se producen por el entrechoque de las semillas.

En este ritual, el ejecutante es otro taita que, en posición de rodillas, interpreta el sonajero de semilla y acompaña al bombo que se encuentra sonando. La función del sonido generado por el sonajero es para purificar la tierra, el aire, el agua y el fuego. En este caso la comunicación se efectúa entre el Hana 


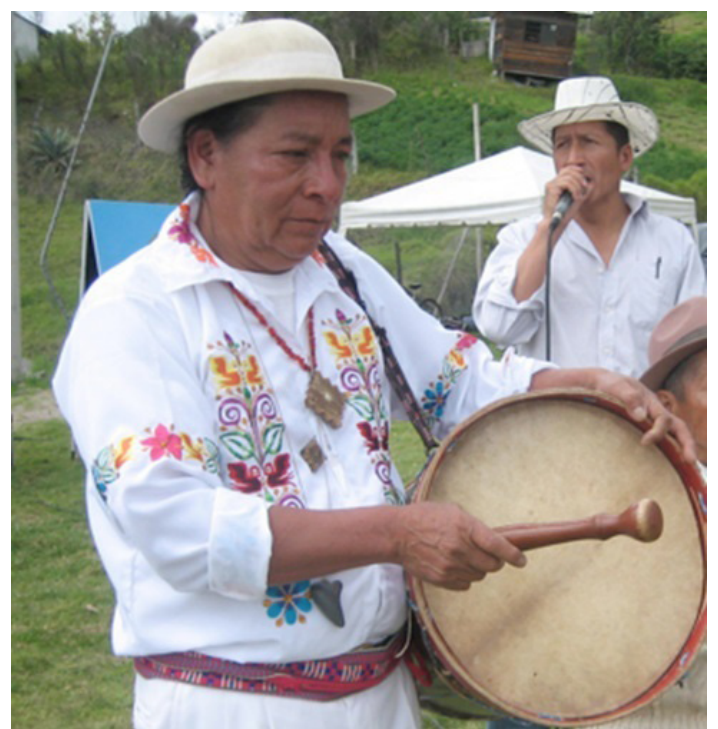

Figura 8. Bombo.

Drum.

pacha-arriba- el Kay pacha -aquí- y el Uku pacha -adentro-. El sonajero acompaña también la ejecución del pinkullu, repitiendo una estructura rítmica fija de tres corcheas por cada tiempo en compás de 6/8. Su ejecución no es uniforme, por momentos sale del pulso y luego lo retoma (Figura 9).

\section{Música y ritual}

Con los lenguajes sonoros, los comuneros cañaris intervienen en el mundo de los espíritus y viceversa, dándole fundamento a miradas diferenciadas de estos hechos sociales dependiendo del lugar que se ocupe. Es lo que Brabec de Mori (2015), Lewy (2015) y Viveiros de Castro (1998), denominan el perspectivismo. En este marco de ritualidad, el lenguaje polifónico generado por la kipa, el pinkullu, el wankar y la maraca o chac cha, establecen puentes de comunicación entre dimensiones vitales diferentes, como la relación entre el mundo humano del aquí, mundos no humanos de las potencias y entes espirituales, dando paso al cumplimiento de los principios de la cuatripartición cosmogónica cañari como la correspondencia, reciprocidad, relacionalidad y complementariedad (Estermann 2006). Así, el performance sonoro, entendido como manifestación de la cultura viva cañari, genera la relacionalidad entre creadores, actores y espectadores a través del diálogo sonoro de los instrumentos musicales (Taylor y Fuentes 2011). Los taitas cañaris afirman que la música, al ser parte de la ofrenda que los humanos dan a las fuerzas del cosmos, cumple con el principio de la correspondencia con los mundos de la cuatripartición, lo que les otorga a los humanos los elementos necesarios para vivir e interactuar.

El efecto de reciprocidad se cumple cuando la Allpa Mama da la materia prima y el humano devuelve con música esa dádiva. Por ejemplo, la Allpa Mama brinda para el pinkullu el carrizo, mismo que se confecciona en forma de flauta; para el wankar da el tronco de los árboles y la piel de los animales; para la maraca o chac cha, da las semillas y calabazas y desde el mar, parte integral del universo cañari, se construyen las kipas. De esta manera se cumple con el principio de la complementariedad entre todos los actores del ritual cañari.

\section{Conclusión}

El Inty Raymi es un performance multimodal (Lewy 2015), donde se combinan música, vestimentas, símbolos,
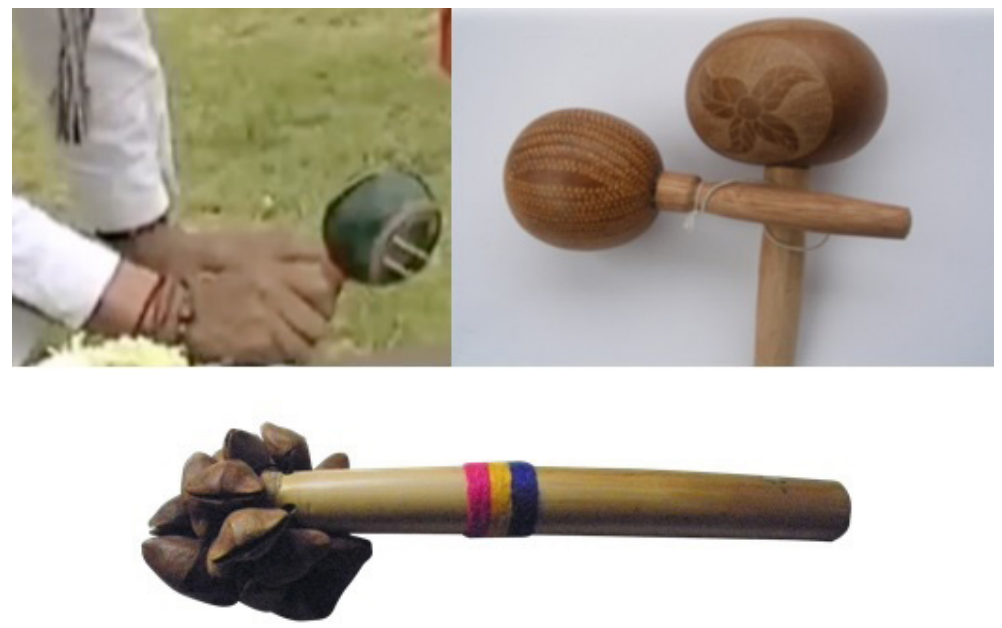

Figura 9. Maraca o chac cha.

Maraca or chac cha. 
oralidad, danzas y actuación. Es aquí donde las sonoridades son una parte fundamental de los ritos organizando eventos (Hill 2015). En el caso del ritual de la Allpa Mama, no hay fertilidad futura sin un ritual presente que la garantice y la ortodoxia del ritual impone que haya música que provenga de instrumentos musicales diseñados para producir sonidos específicos. Los yachak construyen los instrumentos para que desplieguen gamas específicas de timbres, melodías y ritmos, para que respondan a sus respectivas intenciones musicales (Pérez y Gili 2013), como la generada por una kipa de sonidos graves que convoque a las potencias del universo cañari, un pinkullu que fertilice la tierra, un wankar que se alinee con los sonidos del corazón de la Madre Tierra y con un sonajero de semilla que purifique y prepare el entorno para la producción. Es decir, la fecundidad se construye con el diálogo sonoro, cuya textura musical viene dada por la línea melódica del pinkullu, cuyas sonoridades se desenvuelven en una secuencia lineal en torno a la tonalidad de Sol menor, que dialoga con la voz de la kipa que oscila de manera cromática entre el mi y el mi bemol, a manera de bajo continuo. Estas voces se relacionan con el movimiento marcado por la sucesión, no siempre regular, de los instrumentos rítmicos que se desarrollan con las fórmulas de las dos corcheas y silencio de corchea del bombo y de los tresillos de la maraca. Estas relaciones simbólicas que se generan entre la densidad sonora y la fecundidad de la Allpa Mama, mediante la semiótica del sonido, es una alegoría enraizada en el pensamiento colectivo cañari.

En un mundo animista como el cañari, la música y sus instrumentos son entes con voces propias que fungen como medios de comunicación en un entorno mágico-religioso, donde los actores del proceso ritual consuman las relaciones de complementariedad, reciprocidad, relacionalidad y correspondencia exigidas para facilitar las interrelaciones entre los habitantes de la cuatripartición cañari. Hemos visto como la música y sus instrumentos logran las relaciones entre los entes del Uku pacha, Kay pacha, Hana pacha y Hawa pacha. De esta manera el quehacer musical en este ritual funge como mediador en la interacción entre el mundo tangible y el intangible.

El ritual de la Allpa Mama, en el marco del Inty Raymi, es una herramienta epistémica, debido a que en ella se reivindican los saberes ancestrales y se crea un espacio donde lo extraordinario se hace cotidiano, se rompen las dimensiones espaciales y temporales, se conjuga la lógica con la magia, y los seres no humanos -espíritus, deidades y entes- ejercen sus competencias socio culturales junto con los seres humanos. En este contexto las sonoridades adquieren otras estéticas como voces o mensajes de las deidades o de los espíritus de los ancestros, en un diálogo fecundo entre todos los humanos y los no humanos. La función de sacralidad que asumen los instrumentos de invocar, purificar y fecundar es una tradición del pueblo cañari, como potencia vital desde la articulación de diferentes espacios.

Agradecimientos: Los autores expresamos nuestra gratitud a los juicios y sugerencias emitidos por los pares ciegos, que ayudaron a mejorar este artículo y a la revista Chungara por abrirnos sus puertas.

\section{Referencias Citadas}

Acosta, A. 1987. La extirpación de las idolatrías en el Perú. Origen y desarrollo de las campañas. A propósito de Cultura andina y represión, de Pierre Duviols. Revista Andina 5 (1):171-195.

Benenzon, R. 2008. La Nueva Musicoterapia. Lumen, Buenos Aires.

Brabec de Mori, B. 2015. El oído no-humano y los agentes en las canciones indígenas. Un eslabón perdido ontológico. En Sudamérica y sus Mundos Audibles, editado por B. Brabec de Mori, M. Lewy y M. García, pp. 99-119. Ibero-Amerikanisches Institut - Preubicher Kulturbesitz, Berlin.

Cámara de Landa, E. 2003. Etnomusicología. Instituto Complutense de Ciencias Musicales, Colección Música Hispana, Madrid.

Cámara de Landa, E. 2010. El papel de la etnomusicología en el análisis de la música como mediadora intercultural. Historia Actual Online 23:73-84.

Coba, C. 1981. Instrumentos Populares Registrados en el Ecuador. Instituto Otavaleño de Antropología, Otavalo.

Collier, D. y J. Murra 2007. Reconocimiento y Excavaciones en el Austro Ecuatoriano. Casa de la Cultura Ecuatoriana, Núcleo del Azuay, Cuenca.

Cordero, J. 2007. El Imperio Andino del Sol en el Sur Ecuatoriano. Conquista y Dominaciones Incas. 1450-1532. Municipalidad de Cuenca, Cuenca.
Descola, P. 2012. Más Allá de Naturaleza y Cultura. Amorrortu, Buenos Aires.

De Carvalho, P. 1964. Diccionario del Folklore Ecuatoriano. Casa de la Cultura Ecuatoriana, Quito.

De la Peña, G. 1998. Cultura de conquista y resistencia cultural: apuntes sobre el festival de los Tastoanes en Guadalajara. Alteridades 83-89.

Enríquez, P. 2005. Cultura Andina. Editoral Altiplano, Puno.

Estermann, J. 2006. Filosofía Andina. Sabiduría para un Mundo Nuevo. Instituto Superior Ecuménico Andino de Teología (ISEAT), La Paz.

Fernández-Calvo, D. 2007. La representación gráfica de la música de tradición oral. Enfoques y problemas. Revista del Instituto de Investigación Musicológica Carlos Vega 21:175-198.

Garzón, M. 2012. Cañaris del Sur del Ecuador y Mitmaq Cañaris del Perú. Editorial Gráficas Hernández, Cañar.

Grebe, E. 1991. Aportes y limitaciones del análisis musical en la investigación. musicológica y etnomusicológica. Revista Musical Chilena 45 (175):10-18.

Godoy, M. 2005. Breve Historia de la Música del Ecuador. Editorial Ecuador, Quito.

Guaman - Poma de Ayala, F. 1980 [1613]. El Primer Nueva Corónica y Buen Gobierno, editado por J. Murra y R. Adorno. Editorial Siglo XXI, México DF. 
Hill, J. 2015. Discurso ritual, musicalidad e ideologías comunicativas en la Amazonía. En Sudamérica y sus Mundos Audibles, editado por B. Brabec de Mori, M. Lewy y M. García, pp. 181-193. IberoAmerikanisches Institut - Preubicher Kulturbesitz, Berlin.

Hill, J. y J. Chaumeil 2011. Overture. En Burst of Breath. Indigenous Ritual Wind Instruments in Lowland South America, editado por J. Hill y J. Chaumeil, pp. 1-47. University of Nebraska Press, Lincoln.

Hornbostel, E. y C. Sachs 1961 [1914]. Classification of musical instrument. Galpin Society Journal 1:3-29.

Idrovo, J. 1987. Instrumentos Musicales Prehispánicos del Ecuador. Imprenta Monsalve Moreno, Cuenca.

Izikowitz, K.1935. Musical and other Sound Instrument of the South American Indians. A Comparative Ethnographical Study Eleander Boktryckeri Aktiebolag, Goteborg.

Lajo, J. 2002. Qhapaq Kuna más allá de la Civilización. Editorial Grano de Arena, Cusco.

Lewy, M. 2015. Más allá del punto de vista: Sonorismo amerindio y entidades de sonido antropomorfas y no antropomorfas. En Sudamérica y sus Mundos Audibles, editado por B. Brabec de Mori, M. Lewy y M. García, pp. 83-98. Ibero-Amerikanisches Institut - Preubicher Kulturbesitz, Berlin.

López, A. 1995. Tras un método de estudio comparativo entre las cosmovisiones mesoamericana y andina a partir de sus mitologías. Anales de Antropología 32 (1):209-240.

Mansutti-Rodríguez, A. 2006. La demarcación de territorios indígenas en Venezuela: Algunas condiciones de funcionamiento y el rol de los antropólogos. Antropológica 105-106:13-39.

Martínez, J. 1986. El personaje sentado en los keru: Hacia una identificación de los kuraca andinos. Boletín del Museo Chileno de Arte Precolombino 1:101-124.

Mauss, M. 1991. Essai sur le don. Forme et raison de l'echange dans les sociétés archaiques. En Sociologie et Anthropologie, pp. 145-279. Presses Universitaires de France, Paris.

Milla, Z. 2008. Introducción a la Semiótica del Diseño Andino Precolombino. Ediciones Amaru Wayru, Lima.
Nett1, B. 1964. Theory and Method in Ethnomusicology. The Free Press, New York.

Pauta-Ortíz, P. 2013. Transculturación musical en la fiesta del Señor de las Aguas de Girón: Estudio de la apropiación y cambio de rol de la Chirimía y el Violín. Revista del Instituto de Investigación Musicológica Carlos Vega 27:171-195.

Pauta-Ortíz, P. 2017a. Discurso Musical, polisemias e interculturalidad en la Investigación. En Debates sobre la Investigación en Artes. Instituto Latinoamericano de Investigación en Artes (ILIA), pp 92-96. Universidad de las Artes, Guayaquil.

Pauta-Ortíz, P. 2017b. Fiesta del Solsticio de Junio: La Música del Inti Raymi Corpus Christi como Relación Intercultural en las Provincias del Azuay y Cañar (Ecuador). Tesis doctoral, Facultad de Artes, Pontificia Universidad Católica Argentina, Buenos Aires.

Pérez, J. y F. Gili 2013. Clasificación Sach-Hornbostel de Instrumentos musicales: Una revisión y aplicación desde la perspectiva americana. Revista Musical Chilena 67 (219):42-80.

Rivera, J. 2015. El arte de hablar con los cerros: instrumentos musicales, entidades no humanas, cuerpos y géneros en los Andes peruanos septentrionales. En Sudamérica y sus Mundos Audibles, editado por B. Brabec de Mori, M. Lewy y M. García, pp. 255-269. Ibero -Amerikanisches Institut- Preubicher Kulturbesitz, Berlin.

Ruiz-Olabuenaga, J. y M. Ispizua 1989. La Decodificación de la Vida Cotidiana. Métodos de Investigación Cualitativa. Universidad de Deusto, Bilbao.

Stobart, H. 2010. Tara y q'iwa mundos de sonidos y significados En Diablos Tentadores y Pinkillus Embriagadores...en la Fiesta de Anata/Phujllay: Estudios de Antropología Musical del Carnaval de los Andes de Bolivia, Volumen 1, pp. 25-40, editado/compilado por A. Gérard. Plural editores, La Paz.

Taylor, D. y M. Fuentes 2011. Estudios Avanzados de Performance. Fondo de Cultura Económica, México DF.

Viveiros de Castro, E. 1998. Cosmological Deixis and Amerindian Perspectivism. The Journal of de Royal Anthropological Institute 4 (3):469-488.

\section{Notas}

${ }^{1}$ Este enfoque permite definir una estrategia única que se valida para cualquier música. Con este objeto se prescinde del periodo histórico, cultural o estético correspondientes y, por tanto, de las concepciones y categorías utilizadas por los músicos creadores e intérpretes que dan origen a la obra musical. Se opera de acuerdo con diversas concepciones, orientaciones y estrategias. Entre ellas la descomposición del todo musical en sus partes constituyentes para generar una gramática musical; o el desglose de los parámetros físicos del sonido: alturas, duraciones, intensidades, timbres, texturas, etc., para articular relaciones significativas que explican la dinámica interna del discurso musical.

2 La Antropología de la Música permite redescubrir al "hombre" como protagonista del quehacer musical. Abre caminos para comprender la música en sí misma y como parte de un todo sociocultural, posibilitando una aproximación humana, humanista y humanizante al fenómeno sonoro. Se tiende a comprender y analizar el fenómeno musical de acuerdo con los criterios dominantes en un periodo histórico, cultura y estética, considerando como lo perciben, conciben, categorizan y conceptualizan los músicos creadores e intérpretes y sus receptores, en el contexto de sus respectivas matrices socioculturales.

${ }^{3}$ Un yachak es un especialista, sabio comunero, con facultades para darle el sentido debido a los códigos sonoros y demás actos rituales.

${ }^{4}$ Según los relatos de los taitas, la interpretación de sonidos altos (agudos) con el uso de otros sonidos (glissandos descendentes) sirven para fecundar la tierra. 